\title{
Viruses and non-allergen environmental triggers in asthma
}

\author{
Florence Chau-Etchepare, ${ }^{1}$ Joshua L Hoerger, ${ }^{2}$ Brooks T Kuhn, ${ }^{1}$ Amir A Zeki, ${ }^{1,3}$ \\ Angela Haczku, ${ }^{1,3}$ Samuel Louie, ${ }^{1}$ Nicholas J Kenyon, ${ }^{1,3}$ Cristina E Davis, ${ }^{4}$ \\ Michael Schivo ${ }^{1,3}$
}

'Pulmonary, Critical Care, and Sleep Medicine, University of California Davis, Sacramento, California, USA

${ }^{2}$ Internal Medicine, University of California Davis, Sacramento, California, USA

${ }^{3}$ Center for Comparative Respiratory Biology and Medicine, University of California Davis, Davis, California, USA ${ }^{4}$ Mechanical and Aerospace Engineering, University of California Davis, Davis, California, USA

\section{Correspondence to}

Professor Michael Schivo, Internal Medicine, University of California Davis, Sacramento, CA 95616 USA; mschivo@ucdavis.edu

Accepted 20 April 2019 Published Online First 27 July 2019

\begin{abstract}
Asthma is a complex inflammatory disease with many triggers. The best understood asthma inflammatory pathways involve signals characterized by peripheral eosinophilia and elevated immunoglobulin E levels (called T2-high or allergic asthma), though other asthma phenotypes exist (eg, T2-low or non-allergic asthma, eosinophilic or neutrophilic-predominant). Common triggers that lead to poor asthma control and exacerbations include respiratory viruses, aeroallergens, house dust, molds, and other organic and inorganic substances. Increasingly recognized non-allergen triggers include tobacco smoke, small particulate matter (eg, $\mathrm{PM}_{2.5}$ ), and volatile organic compounds. The interaction between respiratory viruses and non-allergen asthma triggers is not well understood, though it is likely a connection exists which may lead to asthma development and/or exacerbations. In this paper we describe common respiratory viruses and non-allergen triggers associated with asthma. In addition, we aim to show the possible interactions, and potential synergy, between viruses and nonallergen triggers. Finally, we introduce a new clinical approach that collects exhaled breath condensates to identify metabolomics associated with viruses and non-allergen triggers that may promote the early management of asthma symptoms.
\end{abstract}

\section{INTRODUCTION}

Despite the consensus set of features that define asthma (reversible airflow obstruction caused by bronchial hyper-reactivity, mucus production, and chronic airway inflammation), ${ }^{1}$ asthma is better classified as a syndrome of related heterogeneous diseases with numerous exacerbating factors, overlapping inflammatory mechanisms, and varied responses to standard therapies. The best characterized among these phenotypes is allergic asthma, defined by IgE-mediated sensitization to environmental allergens. These allergens trigger an adaptive inflammatory response leading to asthma symptoms ${ }^{2}$ mediated predominantly by increased production of the cytokines interleukin 4 (IL-4), IL-5, and IL-13 (type 2 inflammation or allergic inflammation (previously called Th2)). ${ }^{3}$ However, approximately $40 \%$ of asthma is not triggered by allergens with a diverse range of factors that may promote asthma development and exacerbations via activation of the innate immune system. ${ }^{5}$

Respiratory viruses are a major trigger for asthma exacerbations, and they can potentiate the development of asthma in children. ${ }^{67}$ Respiratory viruses are mainly thought to worsen both allergic inflammatory pathways ${ }^{7}$ and non-allergic inflammatory pathways. ${ }^{9} 10$ The interaction between virus-associated asthma and non-allergic triggers is an area of active research. In this review, we will discuss respiratory viruses and non-allergen triggers associated with the severity or development of asthma. Specifically, we will discuss exposure to common respiratory viruses, tobacco smoke, fine particulate matter $\left(\mathrm{P} \mathrm{M}_{2.5}\right)$, and volatile organic compounds (VOCs), and we aim to highlight the synergistic or potentiating interactions between respiratory viruses and non-allergen asthma triggers. Finally, we present a paradigm of asthma management based on exhaled breath metabolites. Figure 1 details and contrasts current inflammatory pathways in asthma, T2-high and T2-low, that are of academic and clinical interest.

\section{RESPIRATORY VIRAL INFECTIONS AND ASTHMA}

Wheezing during acute viral respiratory illnesses is seen in $30 \%$ of children under age 3 years, with the majority of these having no lasting respiratory sequelae by the time patients reach late childhood to adulthood. ${ }^{11} 12$ Despite the resolution of symptoms in most patients, the presence of wheeze in children with rhinovirus (RV) and respiratory syncytial virus (RSV) infections is associated with an increased risk of developing chronic asthma by age 6 years. ${ }^{13}$ From infancy to age 6 years, sensitization to common aeroallergens strengthens the association between childhood viral wheeze and subsequent development of asthma. ${ }^{11}{ }^{14}$ Interestingly, children with atopy are more frequently infected with RSV than those without atopy suggesting a multidirectional and more complex genetic and immune relationship between certain asthma phenotypes and these viral pathogens. ${ }^{15}$ Though this described association is significant, 


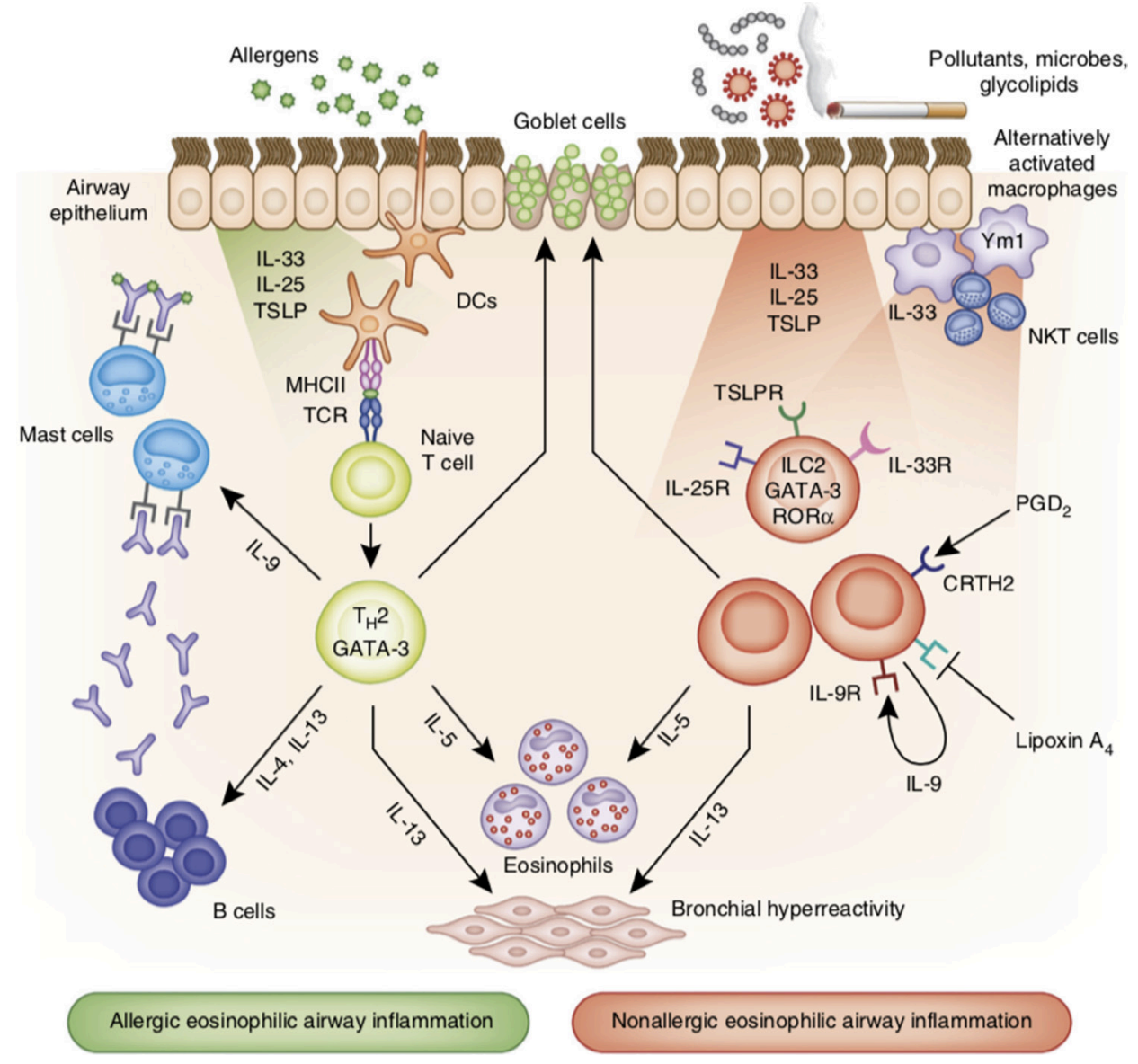

Figure 1 Inflammatory pathways in allergic and non-allergic asthma. In allergic asthma (left) T2 cells (here shown as Th2) drive inflammation and bronchial hyper-reactivity through the production of IL-4, IL-5, and IL-13. IL-4, in particular, drives IgE production. In non-allergic asthma (right) type 2 innate lymphoid cells (ILC2) also produce IL-5 and IL-13, though little IL-4 is produced omitting IgE production. In this classic model, allergens stimulate the T2 response and non-allergen triggers (viruses, tobacco smoke, and particulate matter) stimulate the ILC2 response (adapted from Lambrecht et al). ${ }^{4} \mathrm{CRTH} 2$, prostaglandin D2 receptor; IgE, immunoglobulin E; IL, interleukin; MHCII, major histocompatability 2 complex; NKT, natural killer T cells; PGD2, prostaglandin D2; T2 (Th2), type 2 inflammation; TCR, T cell receptor; TSLP(R), thymic stromal lymphopoietin (receptor); Ym1, M1-polarized macrophage.

allergic sensitization to environmental antigens remains the most significant risk factor for developing asthma. It has been estimated that $85 \%$ of children who develop asthma and up to half of adults who develop new-onset asthma demonstrate allergic responses to aeroallergens. ${ }^{16}$ However, studies have suggested that the interplay of atopy and respiratory viral infection may lead to significant augmentation of asthma risk.

Among children and adolescents who already carry a diagnosis of asthma, more than $80 \%$ of all exacerbations are attributable to acute viral infections. ${ }^{15}{ }^{17} \mathrm{RV}$ and enterovirus are the most common agents in adolescents, while $\mathrm{RV}$ and RSV are more common among children under 3 years. ${ }^{17}$ Influenza $\mathrm{A}$ and $\mathrm{B}$ and coronaviruses are also associated with asthma exacerbations, ${ }^{18}$ though these are less commonly found among exacerbating patients with asthma. However all respiratory viruses show roughly equal potential to trigger an exacerbation once infection is established. ${ }^{19}$ Given the changing seasonal patterns of influenza infections, it is possible that influenza may trigger more asthma exacerbations in years to come.
Identification of viral infection among target populations has been an area of relative success in our understanding of the causes of asthma exacerbations. The viruses associated with asthma exacerbations are easily and relatively inexpensively identified in sputum or nasal lavage via PCR and flow cytometry. ${ }^{18} 19$ Clinically relevant viruses can be identified with high degrees of sensitivity and specificity, and an increasing number of tests are available that allow this identification to be carried out at the point of care by nurses and physicians in the primary care clinic setting. ${ }^{2021}$

Investigation into biomarkers that facilitate prognostication of the clinical course of viral respiratory infections among patients with asthma continues to yield promising leads, but currently no definitive, clinically verified tests have emerged. Children with asthma presenting to healthcare providers with symptomatic wheeze testing positive for viral infection show higher levels of IL-5 and eosinophil cationic protein (ECP) in both serum and nasal samples than either non-infected patients with asthma or infected patients with asthma without symptomatic wheeze. ${ }^{22} 23$ Urinary leukotriene E4 measured during acute viral wheeze 
episodes in preschool children shows elevation above baseline levels measured in the same subjects during periods of remission and compared with healthy controls. ${ }^{24}$ Among adult patients with asthma diagnosed with respiratory viral infections at the time of an asthma exacerbation, sputum interferon-1 $\alpha$ (IFN-1 $\alpha$ ), IFN-1 $\beta$ and IFN- $\gamma$ mRNA levels correlated with severity of symptoms; IL-13, IL-10 and eosinophil major basic protein mRNA levels were greater in patients with viral asthma exacerbations compared with non-exacerbating patients with asthma. ${ }^{18}$ Interferon $\lambda s$, or type III interferons, have recently been described as facilitating immune dysregulation at the airway mucosa in response to respiratory virus infections, and these signaling molecules may play a role in asthma development and exacerbations. ${ }^{25}$

A protein of special interest is IFN- $\gamma$-inducible protein 10 (abbreviated as IP-10, also known as CXCL10), a member of the CXC class of chemokines. IP-10 is secreted by immune and non-immune cells alike in response to inflammatory markers (IFN- $\gamma$, TNF- $\alpha$, and IL- $1 \beta$, among others) and promotes activation of numerous downstream pathways that are implicated in the activation, replication, and differentiation of lymphocytes and monocytes. ${ }^{26}$ Among children with asthma and adults, serum IP-10 levels increase during acute exacerbation, with virally induced exacerbations generating greater elevations than those with other triggers. ${ }^{27}{ }^{28}$ It is not yet clear how viruses induce epithelial IP-10 release, though it appears that active viral replication is necessary as UV-inactivated RV did not generate elevated IP-10 levels. In a study of 63 children with asthma, serum IP-10 levels $>38.9 \mathrm{pg} / \mathrm{mL}$ were $85 \%$ sensitive and $47 \%$ specific for diagnosing virus-induced asthma (although a negative correlation between IP-10 levels and age limits generalizability to adults). ${ }^{28} \mathrm{~A}$ study of 11 subjects with asthma (ages unspecified) experimentally inoculated with RV showed peak cold symptoms at 3.7 days, followed by peak asthma symptoms at 5.8 days; IP- 10 measured by nasal lavage showed a mean increase of $247(155-339) \mathrm{pg} / \mathrm{mL}$ from baseline (mean increase of 12 -fold (95\% CI 3 to 40 )) occurring in concert with cold symptoms, providing a 2-day lead time from peak IP-10 to peak asthma symptoms. ${ }^{29}$ Serum IP-10 levels peaked in a similar time frame to nasal lavage, while sputum levels lagged several days behind.

While each of these biomarkers may further our understanding of viral asthma exacerbations and the immune milieu, their current clinical utility is limited by several factors: (1) Lack of specificity to virus-induced exacerbations. (2) Lack of specificity in relation to virus species and strains. (3) Limited data regarding how levels change over the course of an exacerbation. (4) The lack of correlation between these biomarkers and patient clinical course. There are ongoing studies of virus-specific effects in the respiratory tract which may further elucidate the pathogenesis, molecular fingerprints, and clinical manifestations of viral infection in patients with asthma. Table 1 shows established data on viruses, inflammatory markers, and clinical effects.

\section{Respiratory syncytial virus}

The relationship between RSV and asthma is well established. RSV infection in infants can result in acute bronchiolitis, which symptomatically presents like asthma in adults and children resulting in small airways inflammation, mucus production, wheezing, and acute respiratory distress. ${ }^{30} \mathrm{RSV}$ is a common viral infection that affects up to $90 \%$ of children within the first 2 years of life. Children who have been hospitalized with RSV infection are more likely to have atopic sensitization by age 7 years. ${ }^{11}$ In addition, levels of anti-RSV IgE are significantly higher in patients with asthma compared with patients without asthma. Additionally, total serum IgE is associated with serum titers of anti-RSV IgE in patients with asthma further supporting that early RSV infection may favor a T2 inflammatory profile. ${ }^{31}$

Infants older than 2 months of age with a viral bronchiolitis versus a viral infection not associated with bronchiolitis have higher blood eosinophils. ${ }^{32} 33$ In hospitalized infants with RSV-positive bronchiolitis, fluids from nasal lavage showed detectable levels of ECP-a known eosinophil degranulation product that is a marker for eosinophil activation-and leukotriene C4-a soluble inflammatory

Table 1 Respiratory viruses, inflammatory markers, and clinical manifestations

\begin{tabular}{|c|c|c|}
\hline Respiratory viruses & Inflammatory markers & Clinical manifestations \\
\hline Influenza & $\begin{array}{l}\downarrow \text { IL-5 } \\
\uparrow \text { interferon (IFN)- } \gamma \\
\uparrow \text { MCP-1/CCL2, RANTES/CCL5, macrophage } \\
\text { inhibitory protein-1 } \alpha \text { (MIP)-1 } \alpha, / C C L 3, \text { MCP- } \\
3 / C C L 7, \text { eotaxin/CCL11 } \\
\uparrow \text { IL-1 } \beta \text { and ?LL-13 }\end{array}$ & $\begin{array}{l}\text { Though influenza-infected airways do not demonstrate significant eosinophilic response due } \\
\text { to inhibitory effects of IFN } \gamma \text {, non-T2 cytokine IL-1 } \beta \text { and T2 cytokine IL-13 may contribute } \\
\text { to airway hyper-reactivity. Influenza still induces goblet cell metaplasia and mucus } \\
\text { hypersecretion. }\end{array}$ \\
\hline Human rhinovirus (RV) & $\begin{array}{l}\uparrow \mathrm{IL}-5 \\
\uparrow \text { eosinophil cationic protein (ECP) } \\
\uparrow \uparrow \mathrm{IL}-10 \\
\uparrow \uparrow \mathrm{L}-13\end{array}$ & $\begin{array}{l}\text { Cytokine profile favoring eosinophilic inflammation with potential downregulation of T1 } \\
\text { inflammation by IL-10. Increased IL-13 associated with airways hyper-reactivity. } \\
\text { Bronchiolitis in young children with symptoms of wheezing associated with increased risk of } \\
\text { asthma diagnosis in later childhood. }\end{array}$ \\
\hline $\begin{array}{l}\text { Respiratory syncytial } \\
\text { virus }\end{array}$ & $\begin{array}{l}\uparrow \mathrm{MIP}-1 \alpha / \mathrm{CCL} 3, \mathrm{MIP}-1 \beta / \mathrm{CCL} 4 \\
\uparrow \text { leukotriene C4 (LTC4) } \\
\uparrow E C P \\
\uparrow \text { IL-4 } \\
\uparrow \text { VEGF } \\
\uparrow \mathrm{G}-\mathrm{CSF} \\
\uparrow \mathrm{IL}-10 \\
\uparrow \mathrm{IL}-6 \\
\uparrow \mathrm{IFN}-\gamma\end{array}$ & $\begin{array}{l}\text { Mixed type } 1 \text { and type } 2 \text { inflammatory response though the elevation of IL- } 4 \text { does drive } \\
\text { eosinophilic inflammation, airway hyper-reactivity and goblet cell hypersecretion. } \\
\text { Most common cause of bronchiolitis (small airways inflammation, mucus production, } \\
\text { and wheeze) in infants. Infection with respiratory syncytial virus (RSV) is associated with } \\
\text { prolonged type } 2 \text { inflammation even after recovery which may play into development of } \\
\text { atopy. }\end{array}$ \\
\hline
\end{tabular}


Table 2 Non-allergen environmental asthma triggers, inflammatory markers, and clinical effects

Non-allergen environmental triggers

\begin{tabular}{|c|c|c|}
\hline Tobacco & $\begin{array}{l}\uparrow / \downarrow / \leftrightarrow \text { IL-4 } \\
\uparrow / \downarrow \text { IL-5 } \\
\uparrow / \downarrow \text { IL-6 } \\
\uparrow / \leftrightarrow \text { TNF- } \alpha \\
\uparrow / \downarrow / \leftrightarrow \text { interferon (IFN)- } \gamma\end{array}$ & $\begin{array}{l}\text { Varied and inconsistent data pattern of inflammatory response to } \\
\text { tobacco smoke. Adults, children, men and women may demonstrate } \\
\text { different responses. } \\
\text { Clinically, tobacco smoke exposure is well associated with increased } \\
\text { frequency and severity of symptoms in patients with asthma. }\end{array}$ \\
\hline $\begin{array}{l}\text { Particulate matter } 2.5\left(\mathrm{PM}_{2.5}\right) \\
\text { Diesel exhaust particles (DEPs) } \\
\text { Wildfire smoke }\end{array}$ & $\begin{array}{l}\text { } e o s i n o p h i l \text { cationic protein (ECP) } \\
\text { } \text { eotaxin } \\
\uparrow I L-5 \\
\uparrow / \leftrightarrow \text { IL-6 } \\
\uparrow I L-4 \\
\uparrow I L-8 \\
\downarrow I L-12 \\
\downarrow I F N \gamma \\
\uparrow T N F-\alpha \\
\uparrow I L-8 \\
\uparrow V E G F\end{array}$ & $\begin{array}{l}\text { DEP exposure stimulates type } 2 \text { inflammation and eosinophilic } \\
\text { infiltration, mucus production and airway hyper-responsiveness. } \\
\text { Neutrophilic recruitment via IL-8, mucus hypersecretion, increased } \\
\text { airway hyper-responsiveness. }\end{array}$ \\
\hline $\begin{array}{l}\text { Volatile organic compounds (VOC) } \\
\text { Toluene } \\
\text { Formaldehyde } \\
\text { Limonene }\end{array}$ & $\begin{array}{l}\text { Hapten formation and IgE-mediated response } \\
\downarrow \text { neuroendopeptidase and excess tachykinins } \\
\uparrow \text { IL-4 } \\
\uparrow I F N-\gamma\end{array}$ & $\begin{array}{l}\text { Oxidative stress and neurogenic pathway-mediated bronchospasm. } \\
\text { Neutrophilic inflammation. Eosinophilic inflammation via recognition of } \\
\text { hapten as an antigen and IL-4. } \\
\text { Associated with decline in spirometry and peak flow with increased } \\
\text { dyspnea scores. }\end{array}$ \\
\hline
\end{tabular}

mediator seen in patients with asthma. Interestingly, there is a significant correlation between the two, suggestive of an eosinophilic origin for the leukotriene response in RSV bronchiolitis. 3133

In an in vitro study to assess chemokine expression in RSV infection, human epithelial respiratory cells infected with RSV showed increased production of macrophage inhibitory protein- $1 \alpha$ (MIP- $1 \alpha)$ on days 3 through 5 postinoculation with active virus. ${ }^{34}$ This chemokine is also detected in lower respiratory secretions sampled from intubated infants with RSV bronchiolitis. MIP- $1 \alpha$ levels positively correlate with levels of ECP isolated from RSV-infected patients' lower respiratory secretions suggesting that RSV-related production of MIP- $1 \alpha$ is important in the recruitment and activation of eosinophils. The study also found that lower respiratory tract secretions had higher levels of eosinophil-derived neurotoxin in RSV-infected patients again indicating higher eosinophilic-specific inflammation.

Another study examining infants 7 months and younger infected with RSV showed that their nasopharyngeal secretions had higher levels of IL-4, a key cytokine that mediates airway hyper-responsiveness and a potential target for asthma therapy, as compared with healthy control subjects. ${ }^{35}$ There was even greater elevation in IL-4 in samples from subjects younger than 3 months suggesting a more pronounced T2 inflammatory response in younger infants. This also was true of MIP-1 $\beta$ and ECP, again suggesting significant recruitment and activation of eosinophilic inflammation in RSV infection.

While not fully understood, the significance of the relationship between RSV and its inducible inflammatory profile has some interesting correlations with asthma. In a study examining the nasopharyngeal aspirate in RSV-infected children, even a year after infection, subjects had a persistent elevation in multiple cytokines including MIP-1 $\alpha$, MIP-1 $\beta$, and IL-4. ${ }^{36}$ Other cytokines identified at persistently elevated levels post RSV-infection include VEGF, G-CSF, IL-10, IL-6, IFN- $\gamma$, IL-7, and IL-13. Of these, VEGF, G-CSF, IL- 6 , and IFN- $\gamma$ have been implicated in the pathogenesis of postviral-induced asthma. G-CSF, IL-6, IL-7, and IL-13 are also elevated in respiratory and plasma samples of patients with asthma. The persistence of these inflammatory markers may indicate that early life viral infection may prime the respiratory epithelium for further aeroallergen sensitization by encouraging adaptive T2 high inflammation and eosinophilic recruitment. A similar hypothesis may be proposed for non-allergen triggers that activate in the innate immune system and type 2 innate lymphoid cells.

While there are many studies linking RSV with asthma-like illnesses in children and the subsequent risk of developing asthma later in childhood, we are only just beginning to understand the complex immune responses to viral infection. The connection between RSV and asthma appears to be an induced and exagerrated T2-high inflammatory response that may persist for months to years. Causality between early infection and development of asthma has been hard to prove, but perhaps one of the more convincing pieces of evidence involves palivizumab, an anti-RSV antibody that has been shown to have $70 \%-80 \%$ efficacy in preventing RSV hospitalization. ${ }^{37}$ Treated patients were followed up to age 6 years. By that time, there was no significant difference in asthma prevalence between treated and untreated groups; however, there was significantly decreased rate of recurrent wheezing in the cohort.

\section{Human RV}

$\mathrm{RV}$ is a very common, widespread pathogen associated with early life bronchiolitis, and it is a frequent inciting factor for asthma exacerbations. This virus binds to respiratory epithelial cells via several receptors, mainly in the upper respiratory tract, including ICAM-1 and CDHR-3 (a cadherin-related protein). $\mathrm{RV}$ is then taken into the cell as an endosome where replication and subsequent release of new viral particles occur. ${ }^{38}$ There are three genetically distinct 
species (RV-A, RV-B, and RV-C) with the most common being RV-A and RV-C. Among each species there are many strains, which lead to re-infection with RV over time. ${ }^{39} \mathrm{RV}$ becomes more prevalent in children at 12 months of age and older. Children with RV-bronchiolitis are more likely to have atopic family members, atopic dermatitis, and peripheral blood eosinophilia. ${ }^{13}$

A follow-up study on American children, a cohort of 259 infant patients with RV-bronchiolitis demonstrated that their risk of having recurrent wheeze at age 3 years was increased with an OR of 10 (CI 95\% 4.1 to 26). ${ }^{40}$ Recurrent wheeze in the third year was associated with asthma at age 6 years with an OR of 26 (95\% CI 8.2 to 80). Again, while the specific cellular and molecular pathways are not completely understood, there are several interesting findings regarding the link between RV-induced inflammation in the respiratory tract and the inflammation in patients with asthma. ${ }^{40}$ Serum cytokine samples from children hospitalized with bronchiolitis secondary to RV or RSV showed that the RV-infected patients tended to have higher prevalence of atopic features. In the acute infection stage, the levels of serum IL-5 and IL-13 were higher compared with the RSV cohort. Moreover these higher levels were related to the atopic features of patients suggesting an interaction between environment, the pathogen, and the host.

IL-10, a T cell regulatory cytokine associated with airway hyper-reactivity, was noted to be elevated significantly in RV-infected patients compared with RSV-infected patients. ${ }^{23}$ Kato et al found that, serum ECP, serum IL-5, and IL-5 in nasal secretions were markedly elevated in patients infected with RV with wheezing. Similar to the data in RSV infection, the current data on RV infection favor a T2-high inflammatory profile. It is postulated that this activity predisposes and primes the immune response often invoked in patients with asthma. ${ }^{41}$

\section{Influenza}

In the last decade, influenza infections have garnered significant media attention due to the severe complications and deaths reported from around the world. Patients with asthma are a vulnerable population during the influenza season, particularly regarding complications of influenza including pneumonia and hospitalizations. ${ }^{42}$ In both adult and pediatric patients admitted to the hospital with influenza, the most common underlying medical condition is asthma. Patients with asthma also have a higher risk of being admitted to the intensive care unit and tend to have a more severe course compared with patients without asthma when admitted for influenza infection. ${ }^{42}$

The pooled prevalence for influenza-associated asthma exacerbation is estimated to be $10 \%$, which is much lower than either RSV or RV. ${ }^{43}$ Infection involves epithelial cells throughout the respiratory tree, including the lower respiratory tract. This leads to cellular necrosis, vacuolization, and eventual desquamation, which exposes a vulnerable basilar epithelium layer above the basement membrane. While influenza infection is implicated in triggering asthma exacerbations, the inflammatory cytokine profiles in infected cells do not match what is known about typical T2-high inflammation in asthma. ${ }^{43}$
In a mouse model in which animals were infected with either an influenza virus or a T2-inducer regimen, mice infected with influenza demonstrated suppressed T2 responses in bronchoalveolar lavage (BAL) fluid and lung tissue histology. ${ }^{44}$ Lung tissue and BAL fluid from influenza-infected mice demonstrated neutrophil, lymphocyte, and macrophage-predominant infiltrates and cell. Mice first infected with influenza then later given the T2-inducer antigen still had reduced eosinophils in BAL fluid and on histology, suggesting that the T1-predominant inflammation typically seen in influenza infection can significantly suppress allergen sensitization and T2-high inflammation. ${ }^{44}$ This study also showed that influenza infection decreased the levels of IL-5 in BAL fluid, which is a key cytokine in eosinophilic bone marrow maturation, trafficking, and recruitment.

What is known about influenza infection and the resulting respiratory tract inflammatory profiles are not congruent to the well-described inflammation cascade as a result of either RSV or RV infection. Though influenza-induced asthma exacerbation may not heavily rely on eosinophilic inflammation that is typically associated with classic asthma, there are several published studies that describe the ways in which influenza leads to asthma exacerbation. In one study, there was noted elevation in the NF- $\mathrm{kB}$-mediated cytokines IL-1 $\beta$, IL- 6 , and IL- 8 in tracheal epithelial cells in addition to elevated IL-6, IL-8 and RANTES in serum postinfluenza infection. A study examining induced sputum in patients with asthma exacerbations infected with influenza A demonstrated significantly increased TNF- $\alpha$ levels compared with sputum from patients with RSV infection and non-infectious triggered asthma exacerbations. ${ }^{45}$ Influx of these proinflammatory cytokines in the airways may stimulate mucus hypersecretion and increased capillary permeability resulting in inflammatory cell influx. Additionally Influenza A has been described to activate histamine release from circulating basophils, which may contribute to airway hyper-reactivity. ${ }^{41}$ Still, the pathway from influenza infection to asthma exacerbation is poorly understood and deserves further investigation in the hope that perhaps targeted therapeutic options will mitigate the risk of morbidity and mortality in patients with asthma.

\section{NON-ALLERGEN ENVIRONMENTAL TRIGGERS OF ASTHMA: ENVIRONMENTAL TOBACCO SMOKE}

The effects of environmental tobacco smoke (ETS) on healthy participants is better characterized than the effects on patients with asthma, but it is reasonable to extrapolate that the effects are correlative.

Among children without asthma, secondhand ETS exposure is associated with higher serum IL-4, IL-5, total IgE, and higher absolute blood eosinophils; the same studies have also found elevated levels of TNF-a and IFN- $\gamma^{46-48}$ Among healthy adult non-smokers, a 1 hour exposure to tobacco smoke yielded increased IL-5 (peaking at 1 hour after completion of exposure), IL-6 (peaking at 1 hour after completion of exposure), TNF- $\alpha$, and IFN- $\gamma$; IL-4 was increased in men but not in women. ${ }^{49}$ However, these findings of broadly increased markers of inflammation in response to tobacco smoke have not been consistently replicated. Matsunaga et al showed a weak inverse relationship 
between chronic tobacco exposure and serum IL-4 that did not reach significance and had no association with IL-2, IL-4, IL-5, IL-6, TNF- $\alpha$, or IFN- $\gamma$ in a group of healthy adolescents. ${ }^{50}$ Wilson et al found that among healthy children, chronic tobacco exposure was associated with lower concentrations of IL-1 $\beta$, IL-4, IL-5, and IFN- $\gamma \cdot{ }^{51}$ Lymphoid tissue from the upper airways of children showed dose-dependent decrease in IFN- $\gamma$ producing lymphocytes, despite no tobacco-related changes in these lymphocyte counts in peripheral blood. ${ }^{52}$

These latter findings suggest that rather than inducing a broad T2-high or T2-low pattern of inflammation, tobacco smoke acts at multiple points throughout these pathways. The effects may be either inhibitory or stimulatory, and the interaction between tobacco smoke and other T1/T2-modulating factors (eg, viruses) may impact the host immune response. Indeed, there are multiple examples of tobacco smoke altering the interaction between upstream and downstream inflammatory mediators. IL-12, an important stimulator of IFN- $\gamma$ production, has been widely seen to be downregulated by tobacco exposure. ${ }^{53} 54$ However a non-asthmatic adult smoking population that showed decreased IL-12 in peripheral lymphocytes, consistent with prior data, had levels of IFN- $\gamma$ similar to their non-smoking counterparts. ${ }^{55}$ This suggests that tobacco smoke may be decoupling the IL-12/IFN- $\gamma$ pathway or modulating IFN- $\gamma$ production via an IL-12-independent mechanism. ETS is also seen to alter the typical T2 pathway; in vitro exposure of healthy airway epithelial cells to tobacco smoke inhibited IL-13-induced production of periostin and chloride channel regulator 1 , which are involved in stimulating inflammatory cell migration and mucous production. ${ }^{56}$

In addition to the diverse, potentially counteracting effects that tobacco smoke may have on inflammatory pathways, the age at which chronic ETS exposure first begins (and the age at which results are measured) may also contribute to large differences in the inflammatory effects between populations.

Maternal smoking during pregnancy is associated with lower levels of IL- 4 and IFN- $\gamma$ sampled at time of birth from cord blood, as well as higher IL-13 in response to dust mite allergen or ovalbumin triggers in animal models; however, there was no association with IL-6, IL-10, IL-13, or TNF- $\alpha .^{5758}$ Lower concentrations of IL- 4 and TNF- $\alpha$ in this population was associated with increased risk of asthma and atopy at age 6 years.

Among children without asthma there was no correlation between prenatal ETS exposure and allergic antibodies, while a dose-dependent effect was found for children with postnatal exposure to ETS during the first few months of life. ${ }^{59}$ A meta-analysis of 36 studies showed that prenatal and immediately postnatal ETS exposures were not associated with increased risk of atopy (as assessed by skin prick sensitization) without asthma, but the study excluded atopic patients with asthma in the analysis; and the correlation between parental smoking and total IgE levels in children (again excluding patients with asthma) was mixed. ${ }^{60}$ Kramer et al found increased allergic sensitization among children exposed to tobacco smoke who also had a sensitized parent, but not among those without a family history, suggesting one possible confounder that may contribute to inconsistent results across multiple previous studies. ${ }^{61}$ In contrast to the IL-4-lowering effects of prenatal ETS exposure, non-smoking adults exposed to tobacco smoke and an allergen showed increased IL-4 (along with IL-5 and IL-13), relative to those who were not exposed to ETS. ${ }^{62}$ The ETS-exposed group had decreased IFN- $\gamma$ similar to prenatal tobacco smoke exposure.

Exposure to tobacco smoke, among smokers and non-smokers alike, has long been recognized as both a contributor to the development of asthma as well as a trigger for asthma exacerbations. ${ }^{63-66}$ Secondhand smoke exposure among asthmatic non-smokers positively correlates with frequency and severity of symptoms as well urgent care and emergency department (ED) visits (although, a ceiling effect appears to eliminate this latter correlation in active smokers). ${ }^{6768}$ In addition to its association with increased frequency of acute exacerbations, tobacco smoke exposure also positively correlates with worse baseline performance on spirometry (lower $\mathrm{FEV}_{1}, \mathrm{FVC}$, and $\mathrm{FEV}_{1} / \mathrm{FVC}$ ) and more frequent upper respiratory infections. ${ }^{69} 70$ However, the effects of tobacco smoke exposure on the inflammatory milieu, particularly as it relates to the classically defined T2-high versus T2-low pathways of asthma, remain poorly understood.

The most well defined and consistently demonstrated effect of cigarette smoking on asthmatic inflammatory pathways is the decrease of exhaled nitric oxide (FeNO) levels. T2-high asthma is typically associated with a baseline elevated FeNO compared with a healthy population. However, patients with asthma who demonstrate a typical T2-high inflammatory profile show a dose-dependent decrease in FeNO with tobacco smoke exposure (although levels continue to remain elevated above healthy non-asthmatic mild-to-moderate smokers). ${ }^{71}$ The mechanism and clinical effects of cigarette smoke exposure on FeNO are not yet well understood, and while a decreased baseline FeNO has been reliably observed in allergic patients with asthma with chronic exposed to tobacco smoke, there is evidence of a transient increase in FeNO in the minutes to hours after smoking. ${ }^{72}$ One possible explanation is that smoke leads to increased airway neutrophilia and reduced airway eosinophilia.

For tissue and serum markers of inflammatory pathways, the data on effects of tobacco on patients with asthma are less consistent. Allergic children with asthma with tobacco smoke exposure show higher serum levels of the T2 cytokine IL-13 (a promoter of IgE production as well as goblet cell metaplasia and airway hyper-responsiveness) and IgE than those without smoke exposure. ${ }^{74-77}$ However, serum eosinophils, traditionally elevated in T2 inflammation have been measured as unchanged or decreased in smoking patients with asthma when compared with their non-smoking counterparts. $^{71} 73$ Limited data suggest that among asthmatic adults, smokers do not show significantly different levels of IL-4, IL-5 ,or TNF in bronchial tissues as compared with non-smokers; however, further research is needed to validate these findings. ${ }^{78}$

There are few studies showing synergistic effects of tobacco smoke and respiratory viral infections in the development or exacerbations of asthma. Mouse data show that influenza A-exposed airways have less response to acute $\beta$-adrenergic agonists in the presence of cigarette smoke, though this does not show a clear altered inflammatory 


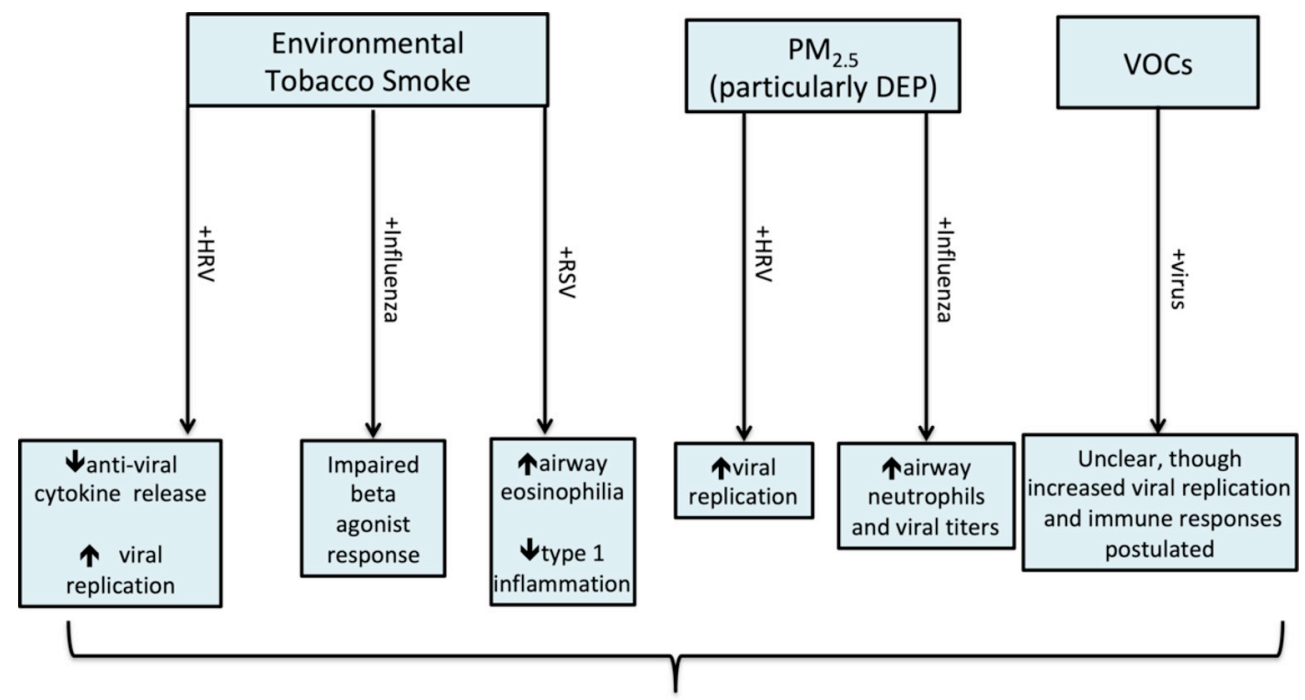

Possible increased asthma symptom severity, exacerbation severity, and exacerbation frequency

Figure 2 Summary of known and postulated synergistic effects of environmental exposure and common viral infections. DEP, diesel exhaust particles; HRV, human rhinovirus; $\mathrm{PM}_{2.5}$ particulate matter 2.5 microns or smaller; RSV, respiratory syncytial virus; VOC, volatile organic compounds.

pathway. ${ }^{79}$ Neonatal mice exposed to sidestream tobacco smoke showed increased BAL eosinophils and T inflammation suppression when infected with RSV. ${ }^{80}$ More compelling evidence showed that cultured human airway cells treated with tobacco smoke and exposed to human RV have decreased antiviral cytokine production (CXCL10 and IFN- $\beta$ ), increased RV replication, and a persistent impaired viral response for more than 24 hours after tobacco smoke treatment. ${ }^{81}$ While other in vitro studies have yielded mixed results, most postulate that tobacco smoke alters an airway cell's inflammatory pathways in an additive way with $\mathrm{RV}^{82-84}$ Though not focusing on asthma per se, a retrospective case-control study looking at children infected with influenza showed increased intensive care needs, intubation rates, and longer hospitalizations in subjects exposed to secondhand smoke compared those not exposed. ${ }^{85}$ Infants admitted with severe RSV bronchiolitis had lower oxygen saturations and were more likely to have a family history of atopy if they were exposed to secondhand tobacco smoke. ${ }^{86}$ These clinical data provide a strong rationale that tobacco smoke alters airway and host immunity with respect to respiratory viral infections, though it does not show a synergistic development of a specific asthma phenotype. Further studies will need to look at how tobacco smoke sensitizes people to respiratory viruses and the potential synergistic development or worsening of asthma. Figure 2 illustrates the synergistic relationship between ETS and virus infections regarding asthma.

\section{PARTICULATE MATTER, WILDFIRE SMOKE, AND TRAFFIC-RELATED AIR POLLUTION}

Fine airborne particulate matter, especially matter with a diameter of less than $2.5 \mu \mathrm{m}\left(\mathrm{PM}_{2.5}\right)$, includes a diverse array of synthetic and naturally occurring substances, whose small size allows them to travel deep into the respiratory tree. $\mathrm{PM}_{2.5}$ consists of small dust and smoke particles, diesel exhaust particles (DEPs), and other industrial by-products, organic carbons, sulfate and nitrate ions, metals and others, with specific composition varying by environment. ${ }^{87}$ In urban environments of industrialized countries (where incidence of asthma is rising), DEPs are the primary constituent of $\mathrm{PM}_{2.5}{ }^{88}$ though other indoor pollutants exist. ${ }^{89}$ Less developed regions frequently have a large particle burden from combustion of biomass fuels, including in-home wood-burning stoves. ${ }^{90}$

Overall exposure to elevated levels of $\mathrm{PM}_{2.5}$ can lead to both acute and chronic respiratory impairment. American children from the general population who were exposed to a 2-week average $\mathrm{PM}_{2.5}$ level of roughly $30 \mu \mathrm{g} / \mathrm{m}^{3}$ from ages 10 years to 18 years were five times as likely to have a decreased $\mathrm{FEV}_{1}$ at age 18 years compared with those with an average $\mathrm{PM}_{2.5}$ level $8 \mu \mathrm{g} / \mathrm{m}^{3}$ (7.9\% vs $\left.1.6 \%\right) .{ }^{91}$ In 1997 , the EPA established an annual standard for $\mathrm{PM}_{2.5}$ of $15 \mu \mathrm{g} /$ $\mathrm{m}^{3}$ and a 24 hours standard of $65 \mu \mathrm{g} / \mathrm{m}^{3}$; in 2012 these standards were revised to $12 \mu \mathrm{g} / \mathrm{m}^{3}$ and $35 \mu \mathrm{g} / \mathrm{m}^{3}$, respectively. ${ }^{92}$ Despite regions in which $\mathrm{PM}_{2.5}$ falls within accepted standards (both at the 1997 and 2012 standards), a difference of $1 \mathrm{IQR}$ in concentrations is associated with decreased $\mathrm{FEV}_{1} /$ FVC in otherwise healthy children and adults, and clinically significant decreases in aerobic fitness. ${ }^{93} 94$

Changes in spirometry correlated to changes in $\mathrm{PM}_{2.5}$ concentration have been noted at 1-8 hours after exposure in patients with asthma and 8 hours to 5 days in healthy subjects. ${ }^{95-97}$ Increases of $10 \mu \mathrm{g} / \mathrm{m}^{3} \mathrm{PM}_{2.5}$ above local baseline is a commonly used metric when assessing effects on asthma. For children with asthma living in industrial areas, such a change is associated with increased hospital visits $0-4$ days postexposure, with a 1.021 relative risk of hospitalization during this time period. ${ }^{98-100}$ A meta-analysis of 26 studies suggest that children under age 5 years are at greatest risk of bronchospasm within 3 days of high $\mathrm{PM}_{2.5}$ exposure. ${ }^{101} 102$ The increased hospitalizations appear to be in the warmer seasons implicating increased outdoor $\mathrm{PM}_{2.5}$ levels. 
Wildfires are an increasing threat in many parts of USA, especially in western USA. It is well documented that wildfires expose many people to high concentrations of $\mathrm{PM}_{2.5}$ in part due to the tremendous wood smoke generated. ${ }^{103}{ }^{2} 04$ Though the data are inconclusive among available studies, wildfires have resulted in adverse health effects, increased health costs, and increased hospitalizations for respiratory and cardiac problems. ${ }^{105} 106$ Asthma admissions and symptoms are particularly increased in children even as the air quality index starts to improve after a wildfire has been controlled. ${ }^{105} 107$ Asthma control is significantly compromised during and after wildfires, ${ }^{108}$ even if lung function itself is not changed. Interestingly, there may be an association between wildfire smoke and obese children with asthma in exacerbation rates and loss of asthma control ${ }^{109}$ suggesting a complex interaction between $\mathrm{PM}_{25}$, asthma, and obesity that may involve non-allergic factors. As wildfires are expected to worsen over the next few years, understanding the relationship between $\mathrm{PM}_{2.5}$ and asthma will need to be a major research priority.

DEPs are the best studied of the common sources of $\mathrm{PM}_{2.5}$, particularly in relation to underlying mechanisms of inflammation. DEPs are a diverse array of constituents including inorganic, metal-containing compounds ( $\mathrm{Ti}, \mathrm{Mn}$, $\mathrm{Cr}, \mathrm{Fe}, \mathrm{Zn}, \mathrm{Pb}$ ), hydrocarbons (aldehydes, benzene, polycyclic aromatic hydrocarbons (PAHs), and nitro-PAHs), nitrogen dioxide, carbon monoxide, and others. ${ }^{88}$ Relative to other sources of $\mathrm{PM}_{2.5}$, exposure to DEP is strongly associated with asthma exacerbations among children living in urban environments. ${ }^{90}$

Effect of DEPs on pulmonary disease appears to be primarily through induction of a strong T2 inflammatory pattern. Children with asthma with chronically elevated exposure to DEP have greater FeNO levels compared with their less-exposed counterparts with asthma. ${ }^{110} 111$ Transient increases in ambient DEPs that occur as part of the typical variability in an urban environment yield increases in $\mathrm{FeNO}$ observed at a 48 -hour lag period. ${ }^{112}$ Increase in ECP on nasal lavage is seen following DEP exposure. ${ }^{113} 114$ Among adults with prior allergen sensitization, a 2-hour exposure to DEPs increased airway eosinophils, ECP, and IL-5 production (measured in lung lavage) in response to an allergen challenge. ${ }^{115}$ Patients with asthma with chronically elevated highway exposure had greater sputum eosinophils relative to peers with lesser exposure. ${ }^{116}$

Examination of the effect of DEPs on IL-6, a promoter of T2 differentiation and inhibitor of Th1 differentiation, has yielded mixed results. ${ }^{117}$ Measurements of IL- 6 in serum and sputum of mine workers collected 2 hours and 5 hours after a 200 min exposure showed increased IL- 6 in both samples relative to pre-exposure baseline. This correlated with a decline in $\mathrm{FEV}_{1}, \mathrm{FVC}$, and $\mathrm{FEV}_{1} / \mathrm{FVC}$ ratio. ${ }^{118}$ Conversely, a different study showed no association between transient variation in ambient DEP levels experienced by truck drivers and IL- 6 measured over the subsequent 48 hours. ${ }^{119}$ However, comparing multiple populations exposed to differing levels, a near doubling of automotive exhaust-associated $\mathrm{PM}_{2.5}$ concentrations $\left(111.1 \mu \mathrm{g} / \mathrm{m}^{3}\right.$ compared with $68.2 \mu \mathrm{g} / \mathrm{m}^{3}$ ) was associated with nearly an order of magnitude greater levels of serum IL-6. ${ }^{120}{ }^{121}$ It has also been shown that differences in DEP (a heterogeneous product with regional component variability) have differing effects on IL-6, with organic components having a predominantly stimulatory effect and non-organic components inhibiting IL-6 production. ${ }^{87}$ IL-4 and IL-8 also increase in patients with asthma with DEP exposure, with the former showing particular elevation during acute exacerbations. ${ }^{122} 123$

In addition to stimulating T2-high inflammation, DEP also appears to independently suppress common mediators of T2-low inflammation. Peripheral IL-12 and IFN- $\gamma$ production are suppressed via an oxidative stress-mediated mechanism in patients with asthma and patients without asthma, alike. ${ }^{124} 125$ Two studies of non-asthmatic tunnel construction workers showed decreased levels of TNF- $\alpha$ after prolonged exposure to high levels of DEP. ${ }^{126}{ }^{127}$ DEP also suppresses the function of natural killer cells, themselves an eradicator of airway eosinophils, leading to prolonged, and dysregulated eosinophilic inflammation in airways. ${ }^{115}$

Though diesel exhaust, and likely other $\mathrm{PM}_{2.5}$ matter, alters a person's immune response, the association between DEP and virus infections in humans is not heavily documented. Several murine studies showing altered airway immune responses to virus infections resulting in increased inflammation and/or impaired lung function. ${ }^{128-131}$ One study looking at DEP exposure and virus titers showed that the combination of DEP and influenza infection results in increased lung neutrophils, increased influenza virus titers, and reduced lung function compared with mice exposed to DEP or influenza alone. ${ }^{131}$ In this study lung impairment was not significantly different between DEP/influenza-exposed vs influenza alone-exposed mice, suggesting that the virus infection exerts the most significant lung damage. In vitro studies looking at airway cells exposed to DEP and influenza virus have shown increased oxidative stress, viral replication, and virus attachment in DEP-exposed cells, ${ }^{132}$ which may be mediated by enhanced TLR3 pathways. ${ }^{133}$ One in vitro study showed enhanced RV replication and species-specific inflammatory cytokine production in nasal epithelial cells exposed to Asian sand dust, a fine particulate found in the Mongolian deserts. ${ }^{134}$

A randomized, placebo-controlled study assessed combined DEP exposure with live attenuated influenza virus on patients with and without nasal allergies. ${ }^{113} \mathrm{DEP} /$ influenza exposure resulted in increased IFN- $\gamma$ production (not associated with allergic patients) and increased eotaxin-1, ECP, and influenza RNA sequences in nasal lavage cells (associated with allergic patients). Although not particular to asthma, these findings suggest a priming of the both non-allergic and allergic cells by DEP to the effects of influenza infection. Altogether, the murine, in vitro, and human studies paint a compelling picture of synergistic activity between $\mathrm{PM}_{2.5}$, DEPs in particular, and respiratory viruses. Further study is needed to determine the magnitude of these interactions on significant clinical outcomes including asthma exacerbations and long-term asthma control (see figure 2).

\section{VOLATILE ORGANIC COMPOUNDS}

The role of VOCs in the potentiation of asthma is an increasingly exciting area of investigation, and will be a focus for the future. VOCs are found in the home and work indoor and outdoor environments; they are produced from 
cosmetics, perfumes, air fresheners, paints, cleaning solutions, and other commonly used chemicals. The developing respiratory tract is universally exposed to VOCs because of their ubiquity in urban environments and in developed countries. Understanding their effects and impact on lung health in vulnerable populations is an area for further research, academically and from a public health perspective.

VOC concentrations are often highest indoors due to lack of circulating air and closed spaces, and early studies examining VOCs demonstrated indoor concentrations of VOCs that are 5-10 times higher than the outdoors. ${ }^{135} 136$ Nocturnal breathlessness has been linked with elevated levels of VOCs and formaldehyde. ${ }^{136}$ Other specific VOCs have been implicated in the development or worsening of asthma symptoms: the presence of limonene has been associated with wheezing and terpene has been associated with a reduction in peak expiratory flow. ${ }^{137}$ Randomized controlled trials have demonstrated that at VOC levels above $25 \mathrm{mg} / \mathrm{m}^{3}$ there is an increase in respiratory symptoms and a decrease in FEF25\%-75\% (mid-expiratory flows) in patients with asthma. ${ }^{138}$

The mechanism of injury to lung epithelium from VOCs is not well understood but is postulated to have multiple pathways that lead to airway sensitization and bronchoreactivity. First, there may be an IgE-mediated pathway in which VOCs need to form haptens with other molecules to create a recognized antigen. ${ }^{139}$ Second, a single agent in high concentration may directly lead to epithelial damage, oxidation, and bronchospasm. ${ }^{140141}$ Finally, there may be disruption of the neurogenic pathway in which irritant VOCs can lead to lower levels of neuroendopeptidase and thus result in the excess of tachykinins, which can play a role in bronchospasm. ${ }^{139}$ One line of evidence assessing periostin levels in asthmatic Korean children exposed to VOCs showed that periostin was negatively correlated with xylene and formaldehyde exposure. ${ }^{142}$ This suggests that VOCs may act through non-T2-high pathways to create asthma symptoms.

While there is significant variation in the compositions of environmental ambient VOC by the time of day and weather patterns, several VOCs have been identified in association with asthma symptoms. Formaldehyde has been linked with causing increased dyspnea and decreased FEV ${ }_{1}{ }^{143}$ A study showed children with a physician diagnosis of asthma or chronic bronchitis were more likely to live in homes in which the formaldehyde concentrations were greater than 41 ppb. ${ }^{144}$ This also demonstrated an inverse relationship between peak expiratory flow measures and formaldehyde concentrations. Franklin et al reported that in patients living in homes with formaldehyde $>50 \mathrm{ppb}$, FeNO was elevated suggesting the association with T2-high inflammation. ${ }^{145}$

Toluene-a hydrocarbon found in many commonly used products such as paint and paint thinners, cleaners and other household products-has also been implicated in asthma. Toluene is often found to be the culprit in occupational asthma and acute bronchohyper-reactivity. ${ }^{146}$ Exposure to toluene has been shown to be associated with significantly lower $\mathrm{FEV}_{1}$, higher medication needs, and increased bronchial reactivity to a methacholine challenge test. ${ }^{146}$ These changes persisted in patients who had continued exposure to the aromatic hydrocarbon. One particularly interesting finding on a molecular level was that toluene haptenized with albumin increased cellular IFN- $\gamma$ and IL-4 production, suggesting a $\mathrm{T}$ cell response and possible influence on the T2 pathway. $^{147}$

Though it is likely that acute or repeated exposure to VOCs would render airways more susceptible to virus infections, to our knowledge there are no clinical or cellular data to support this interaction. As with smoking and $\mathrm{PM}_{2.5}$ exposures, it is highly plausible that inflamed airways alter the binding, cell signaling, and/or viral replication properties of affected airway cells. Future studies from both epidemiologic and in vitro perspectives as well as animal studies may highlight a synergistic relationship between VOCs and viruses on asthma (see figure 2).

\section{FUTURE DIRECTIONS IN UNDERSTANING VIRUSES, NON-ALLERGEN ASTHMA TRIGGERS, AND THEIR INTERACTIONS}

Though there is remarkable progress being made regarding novel treatment options for severe asthma with the advent of biologic therapies, we still need a better understanding of how non-allergen triggers lead to airway inflammation in asthma and acute exacerbations. Moreover, we need a better understanding of how respiratory viruses and non-allergen triggers interact at the airway and systems levels. Ascertaining these mechanisms may help identify the cause of exacerbations earlier, promote recovery, and prevent re-exacerbations. In addition, by knowing which populations are highly susceptible to severe asthma exacerbations (eg, children with secondhand smoke exposure and influenza virus infection), public health efforts may intensify for these groups.

In the current era of personalized 'precision' medicine, the use and monitoring of exhaled breath condensates in the diagnosis and management of asthma is an exciting and rapidly evolving area of investigation. Differences in exhaled breath condensate signals may allow us to differentiate between subjects with and without asthma, and may further allow us to eventually differentiate asthma from other airway diseases such as chronic obstructive pulmonary disease. ${ }^{148-150}$

In our own clinics at the University of California, Davis, we routinely use measures of FeNO, a known marker of eosinophilic airway inflammation, as one part of our assessment of the patient's control of disease based on the American Thoracic Society's published clinical practice guidelines published in 2011. The technology for measuring FeNO has also been standardized. However, there are barriers and limitations to its use. General practices or clinics who care for patients with asthma may not have the means to procure and maintain these tools. Additionally staff needs to be trained to ensure measurements are collected in the appropriate manner and clinicians need to become comfortable with applying this additional data in the entire clinical context of each patient's case. See figure 3 for a proposed algorithm to monitor exhaled breath metabolomic signals to help monitor asthma.

The use of breath metabolomics in patients with asthma has promise in potentially identifying infectious triggers, which are the leading cause for asthma exacerbations worldwide. Ex vivo studies have uncovered significant differences in VOC profiles of virus-infected cells. ${ }^{151} 152$ 


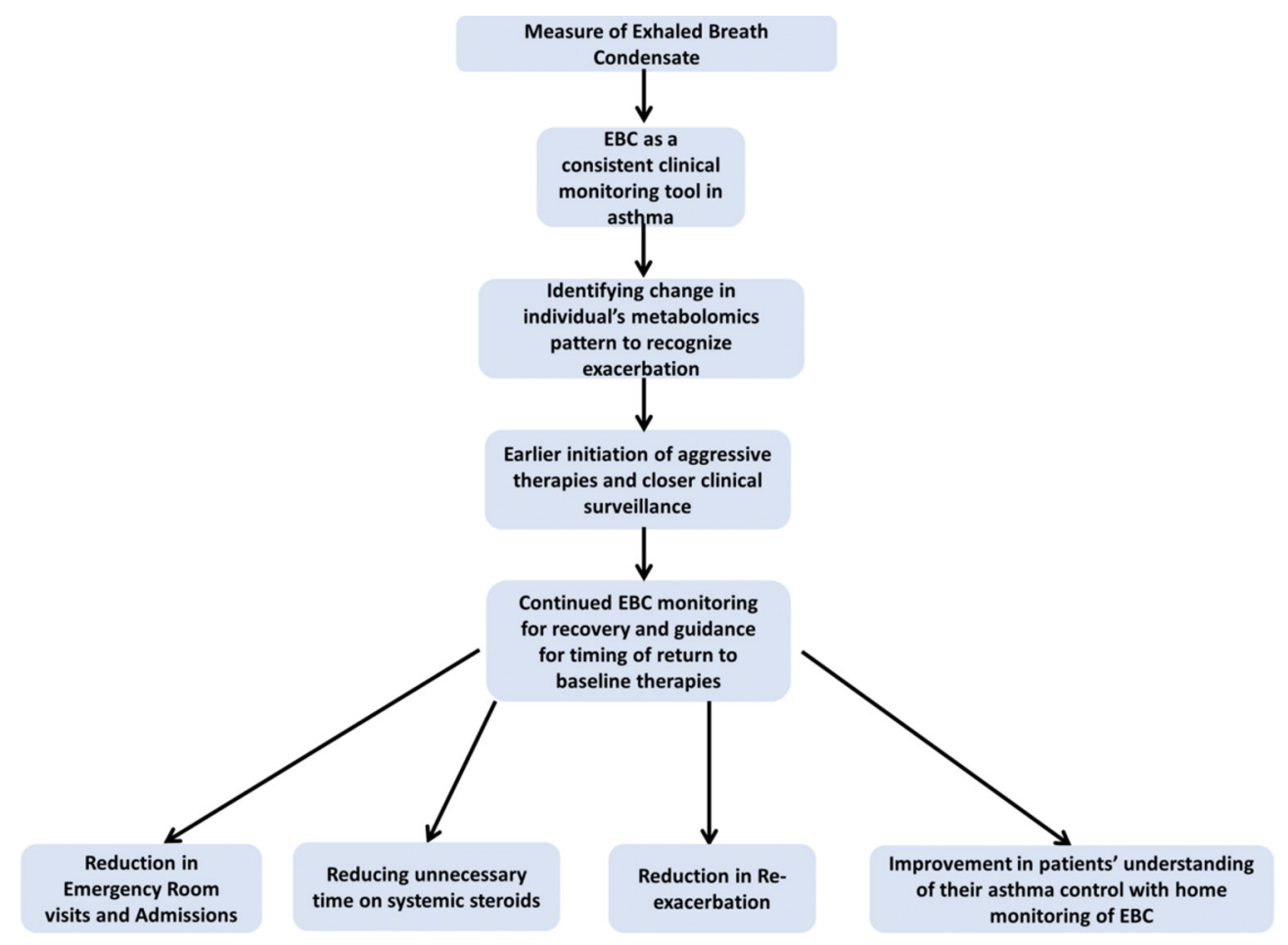

Figure 3 Paradigm of volatile organic compound (VOC) monitoring in asthma. EBC, exhaled breath condensate.

In a European cohort of children with viral respiratory infection, there were markedly different VOC profiles as compared with their uninfected counterparts. Even in the recovery and resolution of symptoms, the altered VOC profile has persisted. ${ }^{153}$

These results have important implications for future research and clinical practice. The routine monitoring of breath metabolomics may be able to help both clinicians and patients identify early changes in airway inflammation which may lead to more expedient and more intense augmentation of therapy, and closer short-term monitoring. This may potentially also reduce the need for hospitalizations or ED visits. Additionally, the continued assessment of breath metabolomics in the recovery phase may also help clinicians identify patients at risk for re-exacerbation and may also be useful in deciding when to de-escalate asthma therapies on recovery.

There is also significant potential in the efforts to measure and monitor environmental and exogenous air pollutants and their role in individual and population-wide effects. Poor understanding of alternations in breath metabolomics in relation to chronic exposures is due to lack of large-scale, longitudinal studies examining these exposures and their correlations to breath metabolomics and clinical states. However, smaller studies and their results suggest this is a worthwhile and relevant area to study. For example, a small plot study involving hospital cleaners when compared with a control group of non-cleaners did show exhaled breath condensate had: (1) Higher $\mathrm{pH}$ and ammonium which supports the concept that we can monitor exposure to ammonia-based cleaning solutions. (2) Higher levels of $\mathrm{H}_{2} \mathrm{O}_{2}$ and 4-hydroxynonenal which may suggest higher oxidative stress in the airways. ${ }^{154}$ Additionally, we know that exposure to $\mathrm{PM}_{2.5}$, such as diesel exhaust, in atopic patients leads to significant changes in airway inflammatory profiles with significant upregulation of both T2-high and T2-low inflammatory markers. ${ }^{115}$ Early childhood exposure to diesel exhaust in allergic patients was strongly correlated with the prevalence of asthma. ${ }^{155}$ As the prevalence of asthma slowly rises in USA and abroad, these findings may be helpful in linking local and regional epidemiological trends in asthma. We may see the increase in airways disease as it relates to concentrations of diesel exhaust and other exogenous volatile compounds that result from the industrialization of third-world countries. Surveillance of $\mathrm{PM}_{2.5}$ compounds may be useful in larger environmental and workplace policy regulations and restrictions.

Although the study of breath metabolomics remains in its infancy, there have been exciting studies that suggest that this may be a useful non-invasive clinical tool in asthma. However, there are several noteworthy limitations to this field: (1) There are no current standardized methods or protocols to collect breath metabolomics with environmental data. (2) Large-scale cohort studies are needed to examine breath metabolomics, first to identify various inflammatory profiles in asthma, and second, to determine the changes that occur naturally over time and with different acute exposures. (3) Trending PM2.5 and other air pollutants over time will be important in understanding the environmental impact humans have on lung disease and other disease states. These early associations and findings both on the individual and population levels are areas worthy of further exploration that can have meaningful personal and large-scale impact on health and healthcare costs.

Contributors All listed authors contributed to the design, writing and editing of the manuscript. All authors are aware of and responsible for the entire content of the manuscript. 
Funding Research reported in this manuscript was partially supported by: $\mathrm{NIH}$, National Heart, Lung, and Blood Institute K23HL127185 (MS); NIH, U01 EB0220003-01 (CED, NJK); NIH, National Center for Advancing Translational Sciences (NCATS), UL1 TR000002 (CED, NJK); NIH, UG3- OD023365 (CED, NJK); and NIH, 1P30ES023513-01A1 (CED, NJK).

Disclaimer The content is solely the responsibility of the authors and does not necessarily represent the official views of the National Institutes of Health.

Competing interests None declared.

Patient consent for publication Not required.

Provenance and peer review Not commissioned; externally peer reviewed.

\section{REFERENCES}

1 Masoli M, Fabian D, Holt S, et al. The global burden of asthma: executive summary of the GINA Dissemination Committee report. Allergy 2004;59:469-78.

2 Schatz M, Rosenwasser L. The allergic asthma phenotype. J Allergy Clin Immunol Pract 2014;2:645-8. quiz 9.

3 Sterk PJ, Lutter R. Asthma phenotyping: TH2-high, TH2-low, and beyond. J Allergy Clin Immunol 2014;133:395-6.

4 Lambrecht BN, Hammad H. The immunology of asthma. Nat Immunol 2015:16:45-56.

5 Arbes SJ, Gergen PJ, Vaughn B, et al. Asthma cases attributable to atopy: results from the Third National Health and Nutrition Examination Survey. J Allergy Clin Immunol 2007;120:1139-45.

6 Priante E, Cavicchiolo ME, Baraldi E. RSV infection and respiratory sequelae. Minerva Pediatr 2018;70:623-33.

7 Hussain SA, Mejias A, Ramilo 0, et al. Post-viral atopic airway disease: pathogenesis and potential avenues for intervention. Expert Rev Clin Immunol 2018:1-10.

8 Martorano LM, Grayson MH. Respiratory viral infections and atopic development: From possible mechanisms to advances in treatment. Eur J Immunol 2018:48:407-14.

9 Santini F. Human respiratory syncytial virus and Th1 chemokines. Clin Ter 2015; 166:e203-8.

10 Makris S, Johnston S. Recent advances in understanding rhinovirus immunity. F1000Res 2018;7:1537.

11 Martinez FD, Wright AL, Taussig LM, et al. Asthma and wheezing in the first six years of life. The Group Health Medical Associates. N Engl J Med 1995;332:133-8.

12 Kusel MM, de Klerk NH, Kebadze T, et al. Early-life respiratory viral infections, atopic sensitization, and risk of subsequent development of persistent asthma. J Allergy Clin Immunol 2007;119:1105-10.

13 Jackson DJ, Gangnon RE, Evans MD, et al. Wheezing rhinovirus illnesses in early life predict asthma development in high-risk children. Am J Respir Crit Care Med 2008;178:667-72.

14 Ulrik CS, Backer V. Markers of impaired growth of pulmonary function in children and adolescents. Am J Respir Crit Care Med 1999;160:40-4.

15 Relić T, Ilić N, Kostić G, et al. Respiratory syncytial virus infection and bronchial hyperreactivity in children up to two years of age in correlation with atopy. Vojnosanit Pregl 2016;73:59-65.

16 Peden DB. Development of atopy and asthma: candidate environmental influences and important periods of exposure. Environ Health Perspect 2000;108(Suppl 3):475-82.

17 Johnston SL, Pattemore PK, Sanderson G, et al. Community study of role of viral infections in exacerbations of asthma in 9-11 year old children. BMJ 1995:310:1225-9.

18 Schwantes EA, Manthei DM, Denlinger LC, et al. Interferon gene expression in sputum cells correlates with the Asthma Index Score during virus-induced exacerbations. Clin Exp Allergy 2014;44:813-21.

19 Cakebread JA, Haitchi HM, Xu Y, et al. Rhinovirus-16 induced release of IP-10 and IL-8 is augmented by Th2 cytokines in a pediatric bronchial epithelial cell model. PLoS One 2014;9:e94010.

20 Mahony JB, Petrich A, Smieja M. Molecular diagnosis of respiratory virus infections. Crit Rev Clin Lab Sci 2011:48:217-49.

21 Caliendo AM. Multiplex PCR and emerging technologies for the detection of respiratory pathogens. Clin Infect Dis 2011;52(Suppl 4):S326-30.

22 Suzuki K, Kato M, Matsuda S, et al. IP-10 Is Elevated in Virus-Induced Acute Exacerbations in Childhood Asthma. Tokai J Exp Clin Med 2016:41:210-7.

23 Kato M, Tsukagoshi H, Yoshizumi M, et al. Different cytokine profile and eosinophil activation are involved in rhinovirus- and RS virus-induced acute exacerbation of childhood wheezing. Pediatr Allergy Immunol 2011;22(1 Pt 2):e87-94.
24 Marmarinos A, Saxoni-Papageorgiou P, Cassimos D, et al. Urinary leukotriene E4 levels in atopic and non-atopic preschool children with recurrent episodic (viral) wheezing: a potential marker? J Asthma 2015;52:554-9.

25 Andreakos E, Salagianni M, Galani IE, et al. Interferon- $\lambda s$ : Front-Line Guardians of Immunity and Homeostasis in the Respiratory Tract. Front Immunol 2017;8:1232.

26 Zhao Q, Kim T, Pang J, et al. A novel function of CXCL10 in mediating monocyte production of proinflammatory cytokines. J Leukoc Biol 2017; 102:1271-80.

27 Wark PA, Bucchieri F, Johnston SL, et al. IFN-gamma-induced protein 10 is a novel biomarker of rhinovirus-induced asthma exacerbations. J Allergy Clin Immunol 2007; 120:586-93.

28 Arikoglu T, Akyilmaz E, Yildirim DD, et al. The relation of innate and adaptive immunity with viral-induced acute asthma attacks: Focusing on IP-10 and cathelicidin. Allergol Immunopathol 2017;45:160-8.

29 Adura PT, Reed E, Macintyre J, et al. Experimental rhinovirus 16 infection in moderate asthmatics on inhaled corticosteroids. Eur Respir $J$ 2014;43:1186-9

30 Lemanske RF. Viruses and asthma: Inception, exacerbation, and possible prevention. J Pediatr 2003;142(2 Suppl):S3-7. discussion S-8.

31 Russell CD, Unger SA, Walton M, et al. The Human Immune Response to Respiratory Syncytial Virus Infection. Clin Microbiol Rev 2017;30:481-502.

32 Rosenberg HF, Dyer KD, Domachowske JB. Respiratory viruses and eosinophils: exploring the connections. Antiviral Res 2009;83:1-9.

33 Harrison AM, Bonville CA, Rosenberg HF, et al. Respiratory syncytical virusinduced chemokine expression in the lower airways: eosinophil recruitment and degranulation. Am J Respir Crit Care Med 1999;159:1918-24.

34 Olszewska-Pazdrak B, Casola A, Saito T, et al. Cell-specific expression of RANTES, MCP-1, and MIP-1alpha by lower airway epithelial cells and eosinophils infected with respiratory syncytial virus. J Virol 1998;72:4756-64.

35 Kristjansson S, Bjarnarson SP, Wennergren G, et al. Respiratory syncytial virus and other respiratory viruses during the first 3 months of life promote a local TH2-like response. J Allergy Clin Immunol 2005;116:805-11.

36 Sigurs N, Gustafsson PM, Bjarnason R, et al. Severe respiratory syncytial virus bronchiolitis in infancy and asthma and allergy at age 13. Am J Respir Crit Care Med 2005; 171:137-41.

37 Resch B. Product review on the monoclonal antibody palivizumab for prevention of respiratory syncytial virus infection. Hum Vaccin Immunother 2017:13:2138-49.

$38 \mathrm{Kim} \mathrm{E}$, Lee $\mathrm{H}$, Kim HS, et al. The effect of rhinovirus on airway inflammation in a murine asthma model. Korean J Pediatr 2013:56:482-9.

39 Jartti T, Korppi M. Rhinovirus-induced bronchiolitis and asthma development. Pediatr Allergy Immunol 2011;22:350-5.

40 Jartti T, Paul-Anttila M, Lehtinen P, et al. Systemic T-helper and T-regulatory cell type cytokine responses in rhinovirus vs. respiratory syncytial virus induced early wheezing: an observational study. Respir Res 2009;10:85.

41 Yamaya M. Virus infection-induced bronchial asthma exacerbation. Pulm Med 2012;2012:1-14

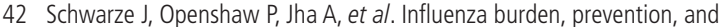
treatment in asthma-A scoping review by the EAACI Influenza in asthma task force. Allergy 2018;73:1151-81.

43 Taubenberger JK, Morens DM. The pathology of influenza virus infections. Annu Rev Pathol 2008:3:499-522.

44 Wohlleben G, Müller J, Tatsch U, et al. Influenza A virus infection inhibits the efficient recruitment of Th2 cells into the airways and the development of airway eosinophilia. J Immunol 2003;170:4601-11.

45 Matsuse H, Tsuchida T, Fukahori S, et al. Differential airway inflammatory responses in asthma exacerbations induced by respiratory syncytial virus and influenza virus a. Int Arch Allergy Immunol 2013;161:378-82.

46 Merghani TH, Saeed A, Alawad A. Changes in plasma IL4, TNFá and CRP in response to regular passive smoking at home among healthy school children in Khartoum, Sudan. Afr Health Sci 2012;12:41-7.

47 el-Nawawy A, Soliman AT, el-Azzouni 0, et al. Effect of passive smoking on frequency of respiratory illnesses and serum immunoglobulin-E (IgE) and interleukin-4 (IL-4) concentrations in exposed children. J Trop Pediatr 1996;42:166-9.

48 Linnamaa $\mathrm{P}$, Nieminen $\mathrm{K}$, Koulu L, et al. Pro-inflammatory and Th2-type cytokine responses in PBMC in infants are associated with parental smoking. Clin Exp Allergy 2012:42:1472-8.

49 Flouris $A D$, Metsios $G S$, Carrillo $A E$, et al. Respiratory and immune response to maximal physical exertion following exposure to secondhand smoke in healthy adults. PLoS One 2012;7:e31880.

50 Matsunaga $\mathrm{Y}$, Vardavas $\mathrm{Cl}$, Plada $\mathrm{M}$, et al. The relationship between cotinine concentrations and inflammatory markers among highly secondhand smoke exposed non-smoking adolescents. Cytokine 2014:66:17-22. 
51 Wilson KM, Wesgate SC, Best D, et al. Admission screening for secondhand tobacco smoke exposure. Hosp Pediatr 2012;2:26-33.

52 Avanzini MA, Ricci A, Scaramuzza C, et al. Deficiency of INFgamma producing cells in adenoids of children exposed to passive smoke. Int J Immunopathol Pharmacol 2006;19:609-16.

53 Opstad TB, Arnesen H, Pettersen A $\AA$, et al. Combined elevated levels of the proinflammatory cytokines IL-18 and IL-12 Are associated with clinical events in patients with coronary artery disease: an observational study. Metab Syndr Relat Disord 2016;14:242-8.

54 Burnham EL, Kovacs EJ, Davis CS. Pulmonary cytokine composition differs in the setting of alcohol use disorders and cigarette smoking. Am J Physiol Lung Cell Mol Physiol 2013;304:L873-82.

55 Opstad TB, Brusletto BS, Arnesen $\mathrm{H}$, et al. Cigarette smoking represses expression of cytokine IL-12 and its regulator miR-21-An observational study in patients with coronary artery disease. Immunobiology 2017;222:169-75.

56 Mertens TCJ, van der Does AM, Kistemaker LE, et al. Cigarette smoke differentially affects IL-13-induced gene expression in human airway epithelial cells. Physiol Rep 2017;5:e13347.

57 Macaubas $\mathrm{C}$, de Klerk NH, Holt BJ, et al. Association between antenatal cytokine production and the development of atopy and asthma at age 6 years. Lancet 2003;362:1192-7.

58 Noakes PS, Holt PG, Prescott SL. Maternal smoking in pregnancy alters neonatal cytokine responses. Allergy 2003;58:1053-8.

59 Lannerö E, Wickman M, van Hage M, et al. Exposure to environmental tobacco smoke and sensitisation in children. Thorax 2008;63:172-6.

60 Strachan DP, Cook DG. Health effects of passive smoking.5. Parental smoking and allergic sensitisation in children. Thorax 1998:53:117-23.

61 Krämer $\mathrm{U}$, Lemmen $\mathrm{CH}$, Behrendt $\mathrm{H}$, et al. The effect of environmental tobacco smoke on eczema and allergic sensitization in children. $\mathrm{Br} J$ Dermatol 2004;150:111-8.

62 Diaz-Sanchez D, Rumold R, Gong H. Challenge with environmental tobacco smoke exacerbates allergic airway disease in human beings. J Allergy Clin Immunol 2006;118:441-6.

63 Mannino DM, Homa DM, Redd SC. Involuntary smoking and asthma severity in children: data from the Third National Health and Nutrition Examination Survey. Chest 2002;122:409-15.

64 Schwartz J, Timonen KL, Pekkanen J. Respiratory effects of environmental tobacco smoke in a panel study of asthmatic and symptomatic children. Am J Respir Crit Care Med 2000;161(3 Pt 1):802-6.

65 Chilmonczyk BA, Salmun LM, Megathlin KN, et al. Association between exposure to environmental tobacco smoke and exacerbations of asthma in children. N Engl J Med 1993;328:1665-9.

66 Chalmers GW, MacLeod KJ, Thomson L, et al. Smoking and airway inflammation in patients with mild asthma. Chest 2001;120:1917-22.

67 Ho G, Tang H, Robbins JA, et al. Biomarkers of tobacco smoke exposure and asthma severity in adults. Am J Prev Med 2013;45:703-9.

68 Pichini S, Basagaña XB, Pacifici R, et al. Cord serum cotinine as a biomarker of fetal exposure to cigarette smoke at the end of pregnancy. Environ Health Perspect 2000;108:1079-83.

69 Lang JE, Dozor AJ, Holbrook JT, et al. Biologic mechanisms of environmental tobacco smoke in children with poorly controlled asthma: results from a multicenter clinical trial. J Allergy Clin Immunol Pract 2013;1:172-80.

70 Eisner MD. Environmental tobacco smoke exposure and pulmonary function among adults in NHANES III: impact on the general population and adults with current asthma. Environ Health Perspect 2002;110:765-70.

71 Jacinto T, Malinovschi A, Janson C, et al. Differential effect of cigarette smoke exposure on exhaled nitric oxide and blood eosinophils in healthy and asthmatic individuals. J Breath Res 2017;11:036006

72 McSharry CP, McKay IC, Chaudhuri R, et al. Short and long-term effects of cigarette smoking independently influence exhaled nitric oxide concentration in asthma. J Allergy Clin Immunol 2005;116:88-93.

73 Giovannelli J, Chérot-Kornobis N, Hulo S, et al. Both exhaled nitric oxide and blood eosinophil count were associated with mild allergic asthma only in non-smokers. Clin Exp Allergy 2016;46:543-54

74 Feleszko W, Zawadzka-Krajewska A, Matysiak K, et al. Parental tobacco smoking is associated with augmented IL-13 secretion in children with allergic asthma. J Allergy Clin Immunol 2006;117:97-102.

75 Yao TC, Chang SW, Hua MC, et al. PATCH study group. Tobacco smoke exposure and multiplexed immunoglobulin $\mathrm{E}$ sensitization in children: a population-based study. Allergy 2016;71:90-8.

76 Moriyama M, Nakamura S. Th1/Th2 Immune Balance and Other T Helper Subsets in IgG4-Related Disease. Curr Top Microbiol Immunol 2017;401:75-83.

77 Hall S, Agrawal DK. Key mediators in the immunopathogenesis of allergic asthma. Int Immunopharmacol 2014:23:316-29.
78 St-Laurent J, Bergeron C, Pagé N, et al. Influence of smoking on airway inflammation and remodelling in asthma. Clin Exp Allergy 2008;38:1582-9.

79 Donovan C, Seow HJ, Bourke JE, et al. Influenza A virus infection and cigarette smoke impair bronchodilator responsiveness to $\beta$-adrenoceptor agonists in mouse lung. Clin Sci 2016;130:829-37.

80 Phaybouth V, Wang SZ, Hutt JA, et al. Cigarette smoke suppresses Th1 cytokine production and increases RSV expression in a neonatal model. Am J Physiol Lung Cell Mol Physiol 2006;290:L222-L231.

81 Logan J, Chen L, Gangell C, et al. Brief exposure to cigarette smoke impairs airway epithelial cell innate anti-viral defence. Toxicol In Vitro 2014;28:1430-5

82 Hudy MH, Traves SL, Wiehler S, et al. Cigarette smoke modulates rhinovirus-induced airway epithelial cell chemokine production. Eur Respir 2010;35:1256-63.

83 Proud D, Hudy MH, Wiehler S, et al. Cigarette smoke modulates expression of human rhinovirus-induced airway epithelial host defense genes. PLoS One 2012;7:e40762.

84 Hudy MH, Traves SL, Proud D. Transcriptional and epigenetic modulation of human rhinovirus-induced CXCL10 production by cigarette smoke. Am J Respir Cell Mol Biol 2014;50:571-82.

85 Wilson KM, Pier JC, Wesgate SC, et al. Secondhand tobacco smoke exposure and severity of influenza in hospitalized children. J Pediatr 2013;162:16-21.

86 Bradley JP, Bacharier LB, Bonfiglio J, et al. Severity of respiratory syncytial virus bronchiolitis is affected by cigarette smoke exposure and atopy. Pediatrics 2005:115:e7-e14.

87 Honda A, Fukushima W, Oishi M, et al. Effects of Components of PM Collected in Japan on the Respiratory and Immune Systems. Int J Toxicol 2017;36:153-64.

88 Wichmann HE. Diesel exhaust particles. Inhal Toxicol 2007;19(Suppl 1):241-4.

89 Habre R, Coull B, Moshier E, et al. Sources of indoor air pollution in New York City residences of asthmatic children. J Expo Sci Environ Epidemiol 2014;24:269-78

90 Habre R, Moshier E, Castro W, et al. The effects of PM2.5 and its components from indoor and outdoor sources on cough and wheeze symptoms in asthmatic children. J Expo Sci Environ Epidemio/ 2014;24:380-7.

91 Gauderman WJ, Avol E, Gilliland F, et al. The effect of air pollution on lung development from 10 to 18 years of age. N Engl J Med 2004;351:1057-67.

92 Environmental Protection Agency. PM2.5 standards [Internet]. 2018 https:// www.epa.gov/criteria-air-pollutants/naaqs-table (cited 23 Dec 2018).

93 Wang BQ, Liu JF, Liu BW, et al. Personal exposure to PM ${ }_{25}$ associated with heavy metals in four travel modes of Tianjin during the summer season. Environ Sci Pollut Res Int 2017;24:6667-78.

94 Cakmak S, Dales R, Leech J, et al. The influence of air pollution on cardiovascular and pulmonary function and exercise capacity: Canadian Health Measures Survey (CHMS). Environ Res 2011;111:1309-12.

95 Moshammer $\mathrm{H}$, Hutter HP, Hauck $\mathrm{H}$, et al. Low levels of air pollution induce changes of lung function in a panel of schoolchildren. Eur Respir J 2006;27:1138-43.

96 Zhang Y, He M, Wu S, et al. Short-Term Effects of Fine Particulate Matter and Temperature on Lung Function among Healthy College Students in Wuhan, China. Int J Environ Res Public Health 2015;12:7777-93.

97 Wu S, Deng F, Hao Y, et al. Fine particulate matter, temperature, and lung function in healthy adults: findings from the HVNR study. Chemosphere 2014;108:168-74.

98 Ding L, Zhu D, Peng D, et al. Air pollution and asthma attacks in children: A case-crossover analysis in the city of Chongqing, China. Environ Pollut 2017;220(Pt A):348-53.

99 Iskandar A, Andersen ZJ, Bønnelykke K, et al. Coarse and fine particles but not ultrafine particles in urban air trigger hospital admission for asthma in children. Thorax 2012;67:252-7.

100 Ko FW, Tam W, Wong TW, et al. Effects of air pollution on asthma hospitalization rates in different age groups in Hong Kong. Clin Exp Allergy 2007;37:1312-9.

101 Huang C, Wang X, Liu W, et al. Household indoor air quality and its associations with childhood asthma in Shanghai, China: On-site inspected methods and preliminary results. Environ Res 2016;151:154-67.

102 Lim H, Kwon HJ, Lim JA, et al. Short-term effect of fine particulate matter on children's hospital admissions and emergency department visits for asthma: a systematic review and meta-analysis. J Prev Med Public Health 2016:49:205-19.

103 Cascio WE. Wildland fire smoke and human health. Sci Total Environ 2018;624:586-95

104 Wegesser TC, Pinkerton KE, Last JA. California wildfires of 2008: coarse and fine particulate matter toxicity. Environ Health Perspect 2009;117:893-7. 
105 Hutchinson JA, Vargo J, Milet M, et al. The San Diego 2007 wildfires and Medi-Cal emergency department presentations, inpatient hospitalizations, and outpatient visits: An observational study of smoke exposure periods and a bidirectional case-crossover analysis. PLoS Med 2018;15:e1002601.

106 Fann N, Alman B, Broome RA, et al. The health impacts and economic value of wildland fire episodes in the U.S.: 2008-2012. Sci Total Environ 2018;610611:802-9.

107 Künzli N, Avol E, Wu J, et al. Health effects of the 2003 Southern California wildfires on children. Am J Respir Crit Care Med 2006;174:1221-8.

108 Vora C, Renvall MJ, Chao P, et al. 2007 San Diego Wildfires and Asthmatics. Journal of Asthma 2011;48:75-8.

109 Tse K, Chen L, Tse M, et al. Effect of catastrophic wildfires on asthmatic outcomes in obese children: breathing fire. Ann Allergy Asthma Immunol 2015;114:308-11.

110 Berhane K, Zhang Y, Salam MT, et al. Longitudinal effects of air pollution on exhaled nitric oxide: the Children's Health Study. Occup Environ Med 2014;71:507-13.

111 Cornell AG, Chillrud SN, Mellins RB, et al. Domestic airborne black carbon and exhaled nitric oxide in children in NYC. J Expo Sci Environ Epidemiol 2012;22:258-66.

112 Sarnat SE, Raysoni AU, Li WW, et al. Air pollution and acute respiratory response in a panel of asthmatic children along the U.S.-Mexico border. Environ Health Perspect 2012;120:437-44

113 Noah TL, Zhou H, Zhang H, et al. Diesel exhaust exposure and nasal response to attenuated influenza in normal and allergic volunteers. Am J Respir Crit Care Med 2012:185:179-85

114 Haworth O, Cernadas M, Levy BD. NK cells are effectors for resolvin $\mathrm{E} 1$ in the timely resolution of allergic airway inflammation. $J$ Immunol 2011;186:6129-35.

115 Carlsten C, Blomberg A, Pui M, et al. Diesel exhaust augments allergeninduced lower airway inflammation in allergic individuals: a controlled human exposure study. Thorax 2016;71:35-44.

116 Epstein TG, Kesavalu B, Bernstein CK, et al. Chronic traffic pollution exposure is associated with eosinophilic, but not neutrophilic inflammation in older adult asthmatics. J Asthma 2013:50:983-9.

117 Diehl S, Rincón M. The two faces of IL-6 on Th1/Th2 differentiation. Mol Immunol 2002;39:531-6.

118 Mehus AA, Reed RJ, Lee VS, et al. Comparison of acute health effects from exposures to diesel and biodiesel fuel emissions. J Occup Environ Med 2015;57:705-12.

119 Chiu YH, Garshick E, Hart JE, et al. Occupational vehicle-related particulate exposure and inflammatory markers in trucking industry workers. Environ Res 2016:148:310-7.

120 Jiang S, Bo L, Gong C, et al. Traffic-related air pollution is associated with cardio-metabolic biomarkers in general residents. Int Arch Occup Environ Health 2016;89:911-21.

121 Lane KJ, Levy Jl, Scammell MK, et al. Effect of time-activity adjustment on exposure assessment for traffic-related ultrafine particles. J Expo Sci Environ Epidemiol 2015;25:506-16

122 Mamessier $E$, Nieves $A$, Vervloet $D$, et al. Diesel exhaust particles enhance T-cell activation in severe asthmatics. Allergy 2006;61:581-8.

123 Chen J, Zhao Q, Liu BB, et al. [Airway oxidative stress and inflammation markers in chronic obstructive pulmonary diseases(COPD) patients are linked with exposure to traffic-related air pollution: a panel study]. Zhonghua Yu Fang Yi Xue Za Zhi 2016;50:411-7.

124 Ohtani T, Nakagawa S, Kurosawa M, et al. Cellular basis of the role of diesel exhaust particles in inducing Th2-dominant response. J Immunol 2005:174:2412-9.

125 Klümper C, Krämer U, Lehmann I, et al. Air pollution and cytokine responsiveness in asthmatic and non-asthmatic children. Environ Res 2015; 138:381-90

126 Stiegel MA, Pleil JD, Sobus JR, et al. Linking physiological parameters to perturbations in the human exposome: Environmental exposures modify blood pressure and lung function via inflammatory cytokine pathway. J Toxicol Environ Health A 2017;80:485-501.

127 Ellingsen DG, Seljeflot I, Thomassen Y, et al. Biomarkers of endothelial activation and thrombosis in tunnel construction workers exposed to airborne contaminants. Int Arch Occup Environ Health 2017;90:309-17.

128 Hahon N, Booth JA, Green F, et al. Influenza virus infection in mice after exposure to coal dust and diesel engine emissions. Environ Res $1985: 37: 44-60$
129 Castranova V, Ma JY, Yang HM, et al. Effect of exposure to diesel exhaust particles on the susceptibility of the lung to infection. Environ Health Perspect 2001;109(Suppl 4):609-12.

130 Gowdy KM, Krantz QT, King C, et al. Role of oxidative stress on dieselenhanced influenza infection in mice. Part Fibre Toxicol 2010;7:34.

131 Larcombe AN, Foong RE, Boylen CE, et al. Acute diesel exhaust particle exposure increases viral titre and inflammation associated with existing influenza infection, but does not exacerbate deficits in lung function. Influenza Other Respir Viruses 2013;7:701-9.

132 Jaspers I, Ciencewicki JM, Zhang W, et al. Diesel exhaust enhances influenza virus infections in respiratory epithelial cells. Toxicol Sci 2005;85:990-1002.

133 Ciencewicki J, Brighton L, Wu WD, et al. Diesel exhaust enhances virus- and poly(I:C)-induced Toll-like receptor 3 expression and signaling in respiratory epithelial cells. Am J Physiol Lung Cell Mol Physiol 2006;290:L1154-L1163.

134 Yeo NK, Hwang YJ, Kim ST, et al. Asian sand dust enhances rhinovirus-induced cytokine secretion and viral replication in human nasal epithelial cells. Inhal Toxicol 2010;22:1038-45.

135 Environmental controls and lung disease. Am Rev Respir Dis 1990:142:915-39.

136 Norbäck D, Björnsson E, Janson C, et al. Asthmatic symptoms and volatile organic compounds, formaldehyde, and carbon dioxide in dwellings. Occup Environ Med 1995:52:388-95.

137 Pappas GP, Herbert RJ, Henderson W, et al. The respiratory effects of volatile organic compounds. Int J Occup Environ Health 2000;6:1-8.

138 Delfino RJ. Epidemiologic evidence for asthma and exposure to air toxics: linkages between occupational, indoor, and community air pollution research. Environ Health Perspect 2002;110(Suppl 4):573-89.

139 Hernández AF, Parrón T, Alarcón R. Pesticides and asthma. Curr Opin Allergy Clin Immunol 2011;11:90-6.

140 Buckpitt A, Boland B, Isbell M, et al. Naphthalene-induced respiratory tract toxicity: metabolic mechanisms of toxicity. Drug Metab Rev 2002:34:791-820.

141 Yoon $\mathrm{HI}$, Hong YC, Cho SH, et al. Exposure to volatile organic compounds and loss of pulmonary function in the elderly. Eur Respir J 2010;36:1270-6.

142 Yon DK, An J, Ha EK, et al. Serum periostin is negatively correlated with exposure to formaldehyde and volatile organic compounds in children. Allergy Asthma Immunol Res 2018;10:716-21.

143 Ezratty V, Bonay M, Neukirch C, et al. Effect of formaldehyde on asthmatic response to inhaled allergen challenge. Environ Health Perspect 2007:115:210-4

144 Garrett MH, Hooper MA, Hooper BM, et al. Increased risk of allergy in children due to formaldehyde exposure in homes. Allergy 1999:54:330-7.

145 Franklin P, Dingle P, Stick S. Raised exhaled nitric oxide in healthy children is associated with domestic formaldehyde levels. Am J Respir Crit Care Med 2000;161:1757-9.

146 Pisati G, Baruffini A, Zedda S. Toluene diisocyanate induced asthma: outcome according to persistence or cessation of exposure. $\mathrm{Br} J$ Ind Med 1993:50:60-4.

147 Lee M, Park S, Park HS, et al. Cytokine secretion patterns of T cells responding to haptenized-human serum albumin in toluene diisocyanate (TDI)-induced asthma patients. J Korean Med Sci 1998;13:459-65

148 Carraro S, Rezzi S, Reniero F, et al. Metabolomics applied to exhaled breath condensate in childhood asthma. Am J Respir Crit Care Med 2007; 175:986-90.

149 Fens N, Zwinderman AH, van der Schee MP, et al. Exhaled breath profiling enables discrimination of chronic obstructive pulmonary disease and asthma. Am J Respir Crit Care Med 2009;180:1076-82.

150 Schivo M, Seichter F, Aksenov AA, et al. A mobile instrumentation platform to distinguish airway disorders. J Breath Res 2013;7:017113.

151 Aksenov AA, Sandrock CE, Zhao W, et al. Cellular scent of influenza virus infection. Chembiochem 2014:15:1040-8.

152 Schivo M, Aksenov AA, Linderholm AL, et al. Volatile emanations from in vitro airway cells infected with human rhinovirus. J Breath Res 2014;8:037110.

153 van der Schee MP, Hashimoto S, Schuurman AC, et al. Altered exhaled biomarker profiles in children during and after rhinovirus-induced wheeze. Eur Respir J 2015;45:440-8.

154 Corradi M, Gergelova P, Di Pilato E, et al. Effect of exposure to detergents and other chemicals on biomarkers of pulmonary response in exhaled breath from hospital cleaners: a pilot study. Int Arch Occup Environ Health 2012;85:389-96.

155 Brandt EB, Biagini Myers JM, Acciani TH, et al. Exposure to allergen and diese exhaust particles potentiates secondary allergen-specific memory responses, promoting asthma susceptibility. J Allergy Clin Immunol 2015;136:295-303. 